\title{
The Impact of Chemical Composition on the Qualitative Indicators of Oil Mixtures
}

\author{
M.B.Adigozalova ${ }^{1}$, G. G. Ismayilov ${ }^{2}$, R.L. Zeynalov ${ }^{3}$ \\ ${ }^{I}$ Assistant professor (PhD), a candidate of chemistry sciences of "Chemistry and inorganic substances \\ technology” department, Azadlig avenue 20, Az 1010, Baku, Republic of Azerbaijan \\ ${ }^{2}$ Doctor of Technical Sciences, Azerbaijan State University of Oil and Industry, Professor of «Oil and gas \\ transportation and storage» Department, 225, D. Alieva ave., Baku, Republic of Azerbaijan. \\ ${ }^{3}$ Doctorant of "Storage of oil-gas transportation" department of Azerbaijan Oil and Industry University
}

*Corresponding Author: G. G. Ismayilov, Doctor of Technical Sciences, Azerbaijan State University of Oil and Industry, Professor of «Oil and gas transportation and storage» Department, 225, D. Alieva ave., Baku, Republic of Azerbaijan.

\begin{abstract}
In the paper, qualitative indicators, the changes in rheological properties of different types of oils and their mixtures have been investigated on the base of laboratory tests. Depending on the type and mass fraction of mixed products, additive changes in the properties for most mixtures, the existence of positive and negative synergism in them have been discovered. In order to prevent the complications associated with the mixing of oils, initially, the necessity of their extensive investigation in laboratory conditions has been shown. One of the main reasons of anomaly that occurs is the chemical composition of the mixed oils (asphalt, paraffin and amount of resin compounds).
\end{abstract}

Keywords: qualitative indicators, density, oil mixing, viscosity, additivity, problematic mixtures, rheological properties, chemical composition, sediments, saturated steam pressure, asphaltenes

\section{MATERIALS AND METHODS}

It's known from oilfield practice that, transportation process of not mono-componential, homogeneous but multi-componential, multiphase heterogeneous systems occurs in mining technological pipelines from exploitation wells to oil producing terminals. However, depending on the time, well product constantly changes its commodity quality in addition to its physical-chemical and rheological properties. Namely for this reason, the number of technical-technological problems and complications occuring in technological pipeline system is more but their solution is hard.

Currently, the number and scope of the scientific researches, being carried out connected with the dependence of qualitative indicators on oils for oil mixtures and their mixing and specific problems occurring in this case, is being expanded. The problems created by "undesirableness" of some mixtures, during extraction, production and transportation of oils, inadmissibility of applying the additivity rule to them indicates the urgency of the problem and importance of solving the problem.

In addition to a number of difficulties occuring during pipeline transportation of different types, rheological oils by being mixed with one another or light oils, as well as solvents, disbalance cases are observed in their storage as well as delivery and reception processes. In this regard, a number of oil and oil products can even be considered "undesirable" couple.

The analysis related with oil losses during the transportation shows that, volume loss can occur in the mixing of the components sharply differing from each other due to their properties. The first normative document on the volume loss occuring in their mixing during the transportation of oils and oil products was published in 1996 by American Oil Institute. Such cases are possible to occur while heavy oils (oil products) are being mixed with light oil products. For instance, the volume obtained by mixing bitumen with light oil can be less than the total volume of the components. It should be noted that, such volume loss is not related to the physical loss of the substance and the total mass of the load remains unchanged during the mixing. 
A number of researches have been devoted to the investigation of the properties of colloids as well as asphaltenes depending on natural oils, nano-colloid asphaltenes behavior in separate oil mixtures. The interpretation of the compound phase diagram of nano-colloid asphaltenes, depending on oils, was first commented by researchers in 2006 [1-3]. Thus, the first versions of phase diagrams of nanocolloid asphaltenes were constructed by the authors and it was determined that, most boundaries of phase conversions are located in practically significant thickness and temperature ranges. The authors also claimed that, the boundaries of phase conversions are connected with "non-conformance" problem during the mixing of oils. In addition to the above mentioned, they emphasized the impossibility of carrying out statistical analysis because of initial data limitation in this area, and showed the necessity of defining approximate values of "crisis" parameters in the future.

The researches determined that, during the transportation of Atabaski (Canada) bitumen, the viscosity is possible to be reduced 40-45\% in standard conditions as a result of mixing it with light oil. However, the viscosity of bitumen-light oil mixture was impossible to be less reduced. Thus, during the transportation of the bitumen with 50\% light oil, a number of difficulties appeared. These problems were mainly due to solid asphaltenes sediments in pipelines. At this time, the creation of the problems for the mixtures in which the quantity of bitumen (i.e. asphaltenes) is less, was almost unexpected. A very interesting problem was discovered in the researches being carried out. So, the mixing sequence of bitumen with light oil being of great importance was revealed. It was determined that, during slight addition of light oil to more quantity of bitumen, the volume of asphaltenes colloid sediment gradually increases and sharp increase in the sediments is due to $67 \%$ amount of light oil in the mixture. On the contrary, when bitumen is added to more quantity of light oil, all asphaltenes instantly deposit being converted to solid colloid particles by adding its first drop. This process undergoes to $33 \%$ density of bitumen [4].

Mixing of different types of oils can lead to the contamination of pipelines and technological devices related to asphaltenes sediment especially when the mixed oils are untraditional and undesirable. Though asphaltenes compounds solve in polar aromatic compounds as toluene, they are not soluble in non-polar paraffin solvents.

Like other oils, the oils being produced in Azerbaijan also are very different according to their physical-chemical and rheological properties. In most cases, the oils of seperate fields differ by their high viscosity, freezing-point, paraffin and asphaltenes compounds in them, as well as irrigation degrees.

It should be noted that, obtaining the data on the qualitative indicators of the mixed oil is important not only for the accounting of oils, but also for predicting the operating modes of the terminals where they are mixed, tanks and processing facilities. Implementing the definition of the main qualitative indicators of different types of oil mixtures was adopted according to strict rules and dependencies in existing normative documents and references. However, as in the world practice, the results of the mixing factor impact of Azerbaijani oil on their physical-chemical and rheological properties show that, the models and calculation schemes concerning ideal solutions considerably vary for these mixtures. For example, commonly accepted additive rule can lead to considerable different results while the parameters for real oil mixtures are being predicted [5].

The following oil mixtures have been analyzed on the base of different types of Azerbaijani oil. For this purpose, crude oils produced in Bulla and Garachukhur fields have been used. Table 1 presents the results of the initial laboratory analysis reflecting the basic rheological and physical-chemical properties of Bulla and Garachukhur oils. As it can be seen from the table, being water-containing oils, selected oils differ by their composition. Laboratory researches have been carried out in different mass fractions and qualitative indicators for mixtures have been determined [5,6]. Physical-chemical properties of these oils, the amount of ballasts in them, and the results on the definition of vanadium, nickel and iron elements by the method of inductive plasma ASTM D 5708 are presented in table 1. The chemical composition impact of the mixed oils and the mixing sequence of oils (i.e. $\mathrm{BN}+\mathrm{QN}$ or $\mathrm{QN}+\mathrm{BN}$ ) were the research object.

Table1. Rheological and physical-chemical properties of Bulla and Garachukhur oils

\begin{tabular}{|c|c|c|c|}
\hline \multirow{2}{*}{ Indicators } & \multicolumn{2}{|c|}{ Original oils } & Analysis method \\
\cline { 2 - 4 } & BN & QN & \\
\hline Density $20^{\circ} \mathrm{C}, \mathrm{kg} / \mathrm{m}^{3}$ & 973,4 & 914,7 & QOST 3900 \\
\hline Kinematik viscosity, $\mathrm{mm}^{2} / \mathrm{s}, 20^{\circ} \mathrm{C}$ & 15,76 & 6,41 & QOST 33 \\
\hline
\end{tabular}




\begin{tabular}{|c|c|c|c|}
\hline \multicolumn{2}{|c|}{} & 13,28 & Chromatography \\
\hline $\begin{array}{c}\text { The amount of resins, \% (mass) } \\
\text { The amount of asphaltenes, } \%\end{array}$ & 10,27 & 0,64 & QOST 11858 \\
\hline The amount of paraffins, \% (mass) & 13,34 & 2,53 & QOST11851 \\
\hline $\begin{array}{c}\text { The definition of saturated steam } \\
\text { pressure, } \mathrm{kPa}\end{array}$ & 16,2 & 9,7 & QOST1756 \\
\hline Freezing point, ${ }^{0} \mathrm{C}$ & +9 & +3 & QOST20287 \\
\hline Mechanical mixtures, \% (mass) & 5,72 & 6,42 & QOST 6370 \\
\hline The amount of salts, mg/l & 480,6 & 530,3 & QOST 21534 \\
\hline The amount of water, \% (mass) & 43,2 & 56,4 & QOST 2477 \\
\hline Vanadium, $\mathrm{mg} / \mathrm{kq}$ & 0,87 & 0,92 & ASTM D 5708 \\
\hline Nickel, $\mathrm{mg} / \mathrm{kg}$ & 1,78 & 1,96 & \\
\hline Iron, $\mathrm{mg} / \mathrm{kg}$ & 4,43 & 4,82 & \\
\hline
\end{tabular}

The change in the qualitative indicators for the mixtures depending on the mass fraction of the mixed product, as well as, the change in the density, viscosity and saturated steam pressure (SSP) of qualitative indicators of the mixtures, depending on the amount of resin, asphalten and paraffin compounds in mixtures in accordance with various mass fractions of oils were investigated and the results are presented in figures 1-3. As it can be seen from figures 1-3, the mixing sequence impact for the oils was not observed. However, a significant impact of the amount of resin, asphalten and paraffin compounds on the density, viscosity and saturated steam pressure of the mixture was observed, but in some cases this impact was distinguished by its anomaly. In comparison with SSP parameter, the density and kinematic viscosity change was more characteristic. Thus, influences of resin in $13-14.5 \%$, asphaltenes in $0.55-0.82 \%$, and paraffin in $8.5-11 \%$ change intervals were observed abnormally (figures 1,2). An event like hysteresis was observed in the change of these parameters, depending on the amount of resin and asphaltens. SSP parameter for oil mixtures was mainly inclined to get decreased by the increase in the amount of resin and asphalten and get increased by paraffin growth (figure 3). One of the interesting results was that, depending on the mass fraction, the change in oil mixtures did not correspond to the additivity, accordingly though the initial amount of resin and asphalten in the B and $\mathrm{G}$ oils was 10.27; 0.23 and 13.28; 0.64 , and certain values increase and decrease in the mass fraction was observed.

There are a number of conclusions on aggregating of asphalten compounds and forming colloid systems in oil mixtures [3]. It is a fact that, the volume increasing of the dependent colloid particles in the mixture leads to abnormal change in the density and viscosity of the mixture. Even there may be such mixtures that, creating a certain volume of phase structure, the sediments in the contact area of the mixed oil components can lead to its complete solidification thanks to sharp increase in the viscosity of that area.

It is known that, high molecular, complicated compounds as resin-asphalten can make oils turn dark, even black color and as they are not stable, these compounds can subject them to various chemical changes, especially oxidation. As regards element composition, resin-asphaltenes are observed with the existence of $\mathrm{C}, \mathrm{H}, \mathrm{S}, \mathrm{N}, \mathrm{O}$ and metal compounds. The presence of resin-asphaltenes in oil content is undesirable, thus, they can lead to blockings and accidents in extraction and transportation of oils by contributing the formation of sediment in pipelines. The researches show that, resin-asphalten substances have a great impact on supplemental oils rheology in case of emergency. Recently, the metals in the content of oils are strictly being controlled in the world market. Metals controlling is being regulated within appropriate standards as ASTM D, EN, ISO, QOST, BP and so on. The metals are mainly in the form of porfirin complex in the content of resin-asphalten substances in oils. The increase in the amount of metals and viscosities is due to resin-asphaltenes growth in oils.

The metals in $\mathrm{B}$ and $\mathrm{G}$ oils produced in Azerbaijan was determined by modern ASTM D 5708 inductive plasma method. Accordingly, V-0.87; $0.92 \mathrm{mg} / \mathrm{kg} ; \mathrm{Ni}-1.78 ; 1.96 ; 3.51 \mathrm{mg} / \mathrm{kg}$ and Fe-4.43; $4.82 \mathrm{mg} / \mathrm{kg}$ in $\mathrm{B}$ and $\mathrm{G}$ oils being under the investigation (table 1).

The results of the researches and scientific analysis show that, the existence and oxidation of metals in oils ( $\mathrm{V}, \mathrm{Ni}, \mathrm{Fe}$ and so on.) are one of the main reasons for the formation of abnormal properties in oil mixtures. At this time those metals are possible to play the role of natural emulgator.

There are water, mechanical mixtures and a number of soluble salts in oil. The main factor impacting on the solution of water and mechanical mixtures in it is its chemical composition. Thus, unlike 
naphten and paraffin carbohydrogens, aromatic and unsaturated ones solve better in water. Solid paraffin in oil solve worse in water, however, resin and asphaltenes form more stable compounds with water thanks to hetroatomic compounds in them. The generated compounds cause the formation of abnormal processes in extraction and transportation of oils.
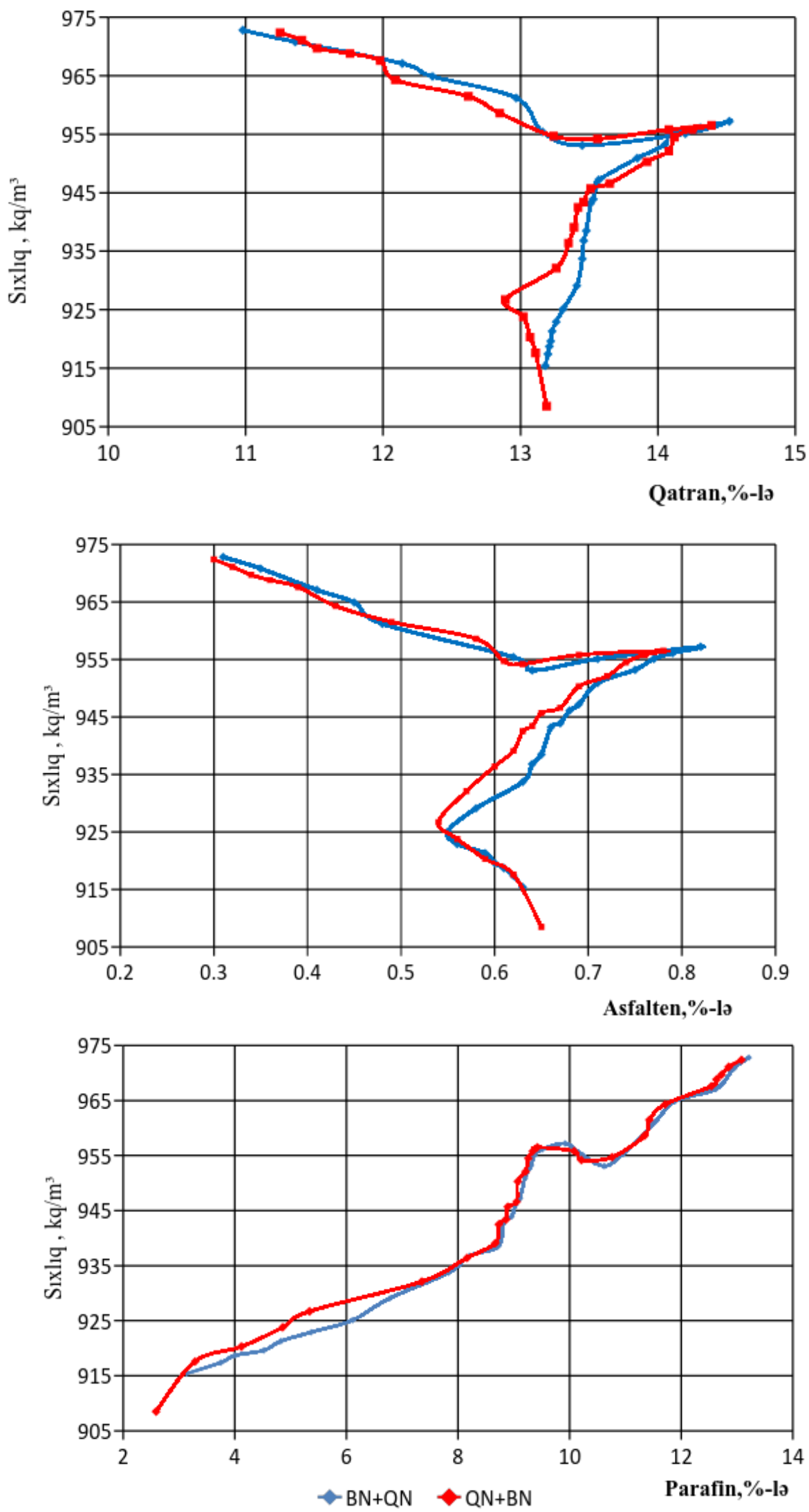

Figure1. The dependence of mixture density on resin, asphalten and paraffin amount. 
The Impact of Chemical Composition on the Qualitative Indicators of Oil Mixtures
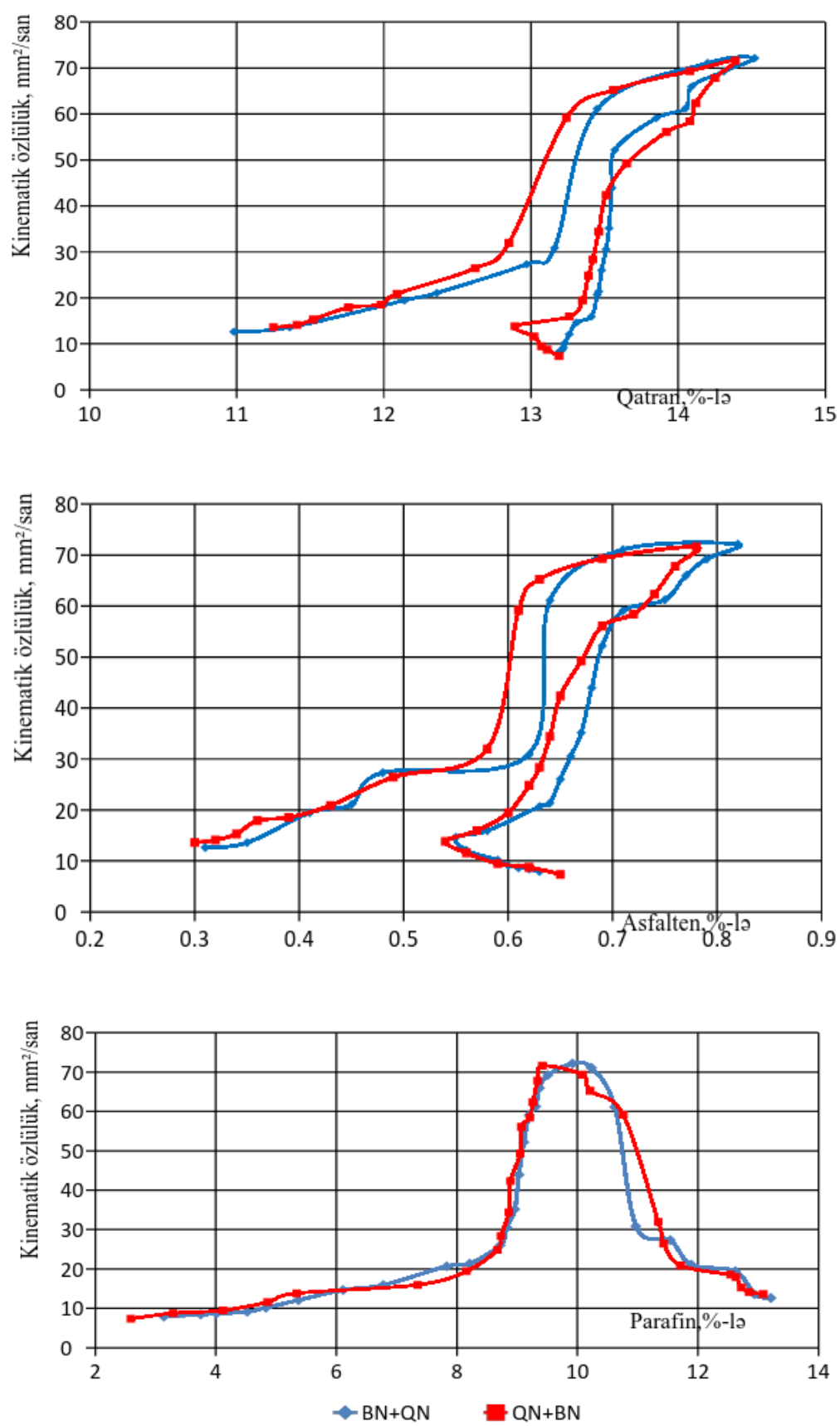

Figure2. The dependence of mixture kinematic viscosity on resin, asphalten and paraffin amount.

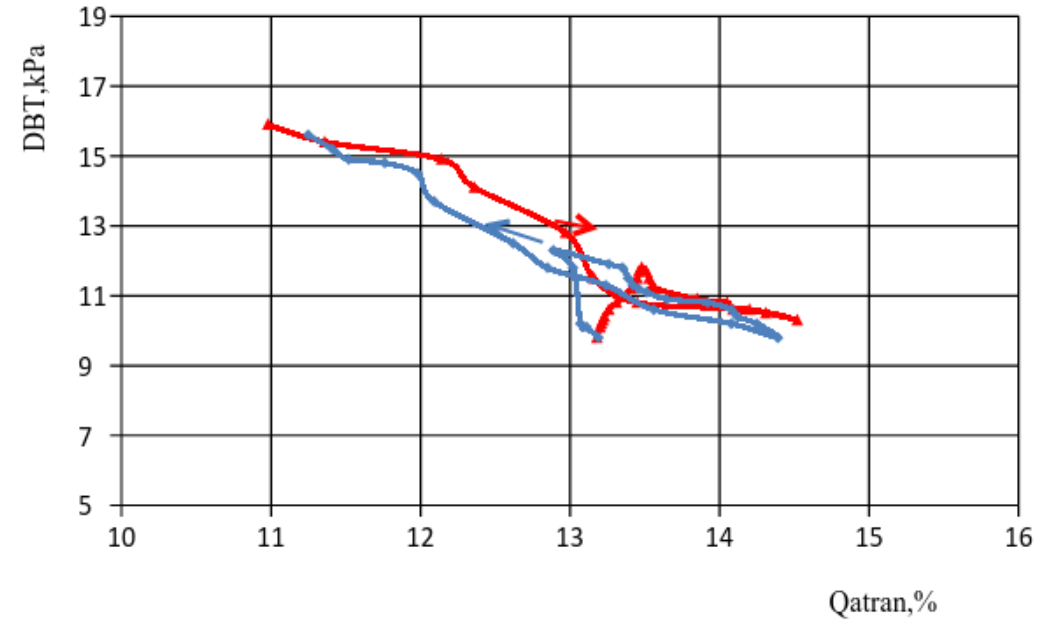



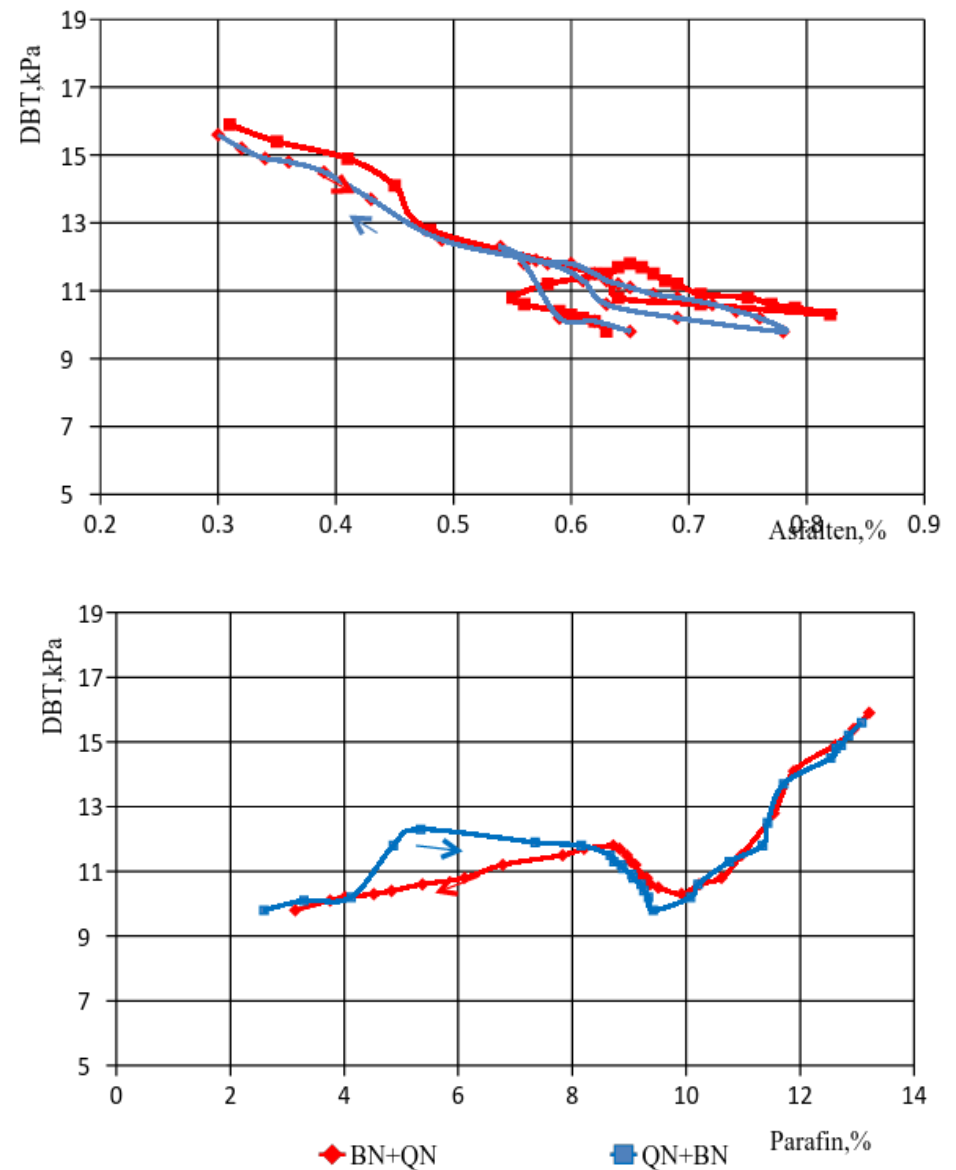

Figure3. The dependence of mixture saturated steam pressure on resin, asphalten and paraffin amount

Sedimentation process of water, mechanical mixtures and resin-asphaltenes-paraffin compounds of the ballasts in oil mixtures being under the investigation was also studied. It should be noted that, complete separation of the sediments in the mixture is impossible while being stored in ordinary condition. Moreover, resin-asphaltenes in oils are of great importance for the formation of stable emulsions. The analysis shows that, the amount of mechanical-mixtures was 1,86\%; resin-asphaltenes $1,08 \%$ in the content of $2,94 \%$ sediment formed within 30 days (table 2) in $\mathrm{G}$ and B mixtures. After the temperature impact (heating up to $65^{\circ} \mathrm{C}$ ), increasing, the amount of the seperated sediments was $4,97 \%$ so that, the major part of it $-4,38 \%$ was formed by mechanical mixtures.

Such change in the resin, asphalten and paraffin masses occurs depending on their structure. This is due to a distinct structure of micro pores between the molecules in resin, asphalten and paraffin before the process. Depending on the size of these pores, absorbed substances (oil, salt, hard water and etc.) change the resin, asphalten and paraffin masses. It should be taken into account that, after any change in the composition of oils and temperature, passing to equilibrium case of asphalten colloids can take some days.

Table2: The results on the definition of the amount of the sediments (ballasts) depending on time and temperature in the mixture in $42: 58 \%$ ratio of $B$ and $G$ oils.

\begin{tabular}{|c|c|c|c|c|c|c|c|c|c|c|c|c|c|c|c|c|}
\hline \multirow{3}{*}{$\begin{array}{l}\text { Indicat } \\
\text { ors }\end{array}$} & \multirow{2}{*}{\multicolumn{7}{|c|}{$\begin{array}{c}\mathrm{T}=20^{0} \mathrm{C} \\
\text { Time, day }\end{array}$}} & \multirow{2}{*}{\multicolumn{9}{|c|}{ Temperature, ${ }^{0} \mathrm{C}$}} \\
\hline & & & & & & & & & & & & & & & & \\
\hline & 1 & 5 & 10 & 15 & 20 & 25 & 30 & 25 & 30 & 35 & 40 & 45 & 50 & 55 & 60 & 65 \\
\hline The & 1,2 & 1,8 & 2,3 & 2,5 & 2,7 & 2,8 & 2,9 & 3,0 & 3,5 & 3,8 & 4,1 & 4,5 & 4,6 & 4,7 & 4,8 & 4,9 \\
\hline $\begin{array}{c}\text { amoun } \\
\text { t of the } \\
\text { sedime } \\
\text { nt } \\
\% \\
\text { (mass) }\end{array}$ & 4 & 9 & 5 & 1 & 9 & 6 & 4 & 9 & 6 & 8 & 9 & 1 & 2 & 5 & 6 & 7 \\
\hline $\begin{array}{c}\text { The } \\
\text { amoun } \\
t \text { of }\end{array}$ & $\begin{array}{c}16 \\
7\end{array}$ & $\begin{array}{c}18, \\
9\end{array}$ & $\begin{array}{c}19, \\
6\end{array}$ & $\begin{array}{c}20, \\
8\end{array}$ & $\begin{array}{c}21, \\
7\end{array}$ & $\begin{array}{c}22 \\
4\end{array}$ & $\begin{array}{c}23, \\
1\end{array}$ & $\begin{array}{c}25 \\
8\end{array}$ & $\begin{array}{c}27, \\
2\end{array}$ & $\begin{array}{c}29, \\
4\end{array}$ & $\begin{array}{c}30 \\
7\end{array}$ & $\begin{array}{c}32, \\
1\end{array}$ & $\begin{array}{c}33 \\
7\end{array}$ & $\begin{array}{c}34 \\
6\end{array}$ & $\begin{array}{c}35, \\
4\end{array}$ & $\begin{array}{c}36, \\
8\end{array}$ \\
\hline
\end{tabular}




\begin{tabular}{|c|c|c|c|c|c|c|c|c|c|c|c|c|c|c|c|c|}
\hline $\begin{array}{c}\text { water, } \\
\% \\
\text { (mass) }\end{array}$ & & & & & & & & & & & & & & & & \\
\hline The & 197 & 209 & 226 & 240 & 260 & 290 & 310 & 320 & 341 & 366 & 385 & 400 & 416 & 427 & 432 & 443 \\
\hline $\begin{array}{c}\text { amoun } \\
\mathrm{t} \text { of } \\
\text { salts, } \\
\mathrm{mg} / \mathrm{l}\end{array}$ &, 8 & 6 &, 3 & ,2 & , 4 & ,8 & ,7 & ,2 & ,7 & ,8 & ,4 & ,9 & 1 & ,5 & ,9 & 6 \\
\hline
\end{tabular}

\section{CONCLUSION}

So, the dependence of qualitative indicators of different type of oil mixtures on their initial properties and mixing process has been shown on the base of Azerbaijani oils. In some cases, during oil mixing, changing qualitative indicators abnormally, and several mixtures creating specific problems and generally their "undesirability" have been discovered. The impossibility of applying additivity rule to such kind of mixtures should be taken into account and with the purpose of obtaining rational mixtures, carrying out initial laboratory analysis should be considered urgent. Thus, as a result of the conducted researches, it was determined that, chemical composition of oil mixtures has a significant impact on their rheophysical properties. Depending on composition variability, during oil mixing, mechanical mixtures, resin-asphalten-paraffin sediment occur. Even at this time, the increase in mass percentage of asphalten and resins is observed in the mixtures of high molecular chemical compounds. The change in the amount of ARP occurs depending on their structure. This is mainly due to a distinct structure of micro-pores between the molecules and structure changing of ARP before the process. Depending on the size of these pores, absorbed substances (oil, salt, hard water and etc.) change the amount of resin, asphalten and paraffin. It also should be taken into account that, after any change in oils composition and temperature, passing to equilibrium case of asphalten colloids can take some days.

\section{REFERENCES}

[1] Evdokimov I.N.. Bifurcated correlations of the properties of crude oils with their asphalting content. // Fuel, 2005, 84 (1): 13-28

[2] Evdokimov I.N., Eliseev N. Yu., Eliseev D. Yu. Thermophysical properties and phase-behavior of asphaltene-containing petroleum fluids. // Fluid Phase Eqilibria, 2003, 212 (1-2) : 269-278

[3] Evdokimov I.N. T-C Phase Diagram of Asphaltenes in Solutions. // Petroleum Science and Technology, 2007, $25(1-2): 5-17$

[4] Dickau R.,Pardo C. Centrifuqal Pumps in Heated Bitumen Pipeline Service //Proceedings of the 21 st International Pump Users Symposium, Baltimore. USA, 2004, p.10-17.

[5] Ismayilov G.G., Nurmammadova R.G., Zeynalov R.L. About synergism and antagonism inclinations during storage and transportation of oil mixtures// Azerbaijan Oil Industry, 2014, N4. P. 31-35.

[6] Ismayilov G.G., Nurmammadova R.G., Nurullayev V.X., Zeynalov R.L. Specific problems connected with oil mixing// Azerbaijan Oil Industry, 2015, N10. P. 30-36.

Citation: G. G. Ismayilov et.al, (2017). The Impact of Chemical Composition on the Qualitative Indicators of Oil Mixtures, International Journal of Petroleum and Petrochemical Engineering (IJPPE), 3(4), pp.111-117, DOI: http://dx.doi.org/10.20431/2454-7980.0304012

Copyright: (c) 2017 G. G. Ismayilov et.al. This is an open-access article distributed under the terms of the Creative Commons Attribution License, which permits unrestricted use, distribution, and reproduction in any medium, provided the original author and source are credited 